\title{
Formulation and Evaluation of Parenteral Sustained Release Microspheres of Diclofenac Sodium
}

\author{
C. Sajeev, R. Archna, V. Gupta, A. Sobti, R. N. Saha* \\ Pharmacy Group, Birla Institute of Technology and Science, Pilani -333 031 (Rajasthan), India.
}

\section{Summary}

The aim of this study was to formulate and evaluate microsphere based depot type parenteral sustained release formulation of diclofenac sodium (DFS). Drug was formulated in the form of microspheres, using varying proportion of ethylcellulose (EC) as the retardant material to extend the release, by phase separation-coacervation technique. The in vitro release pattern of the designed formulations was studied using modified Franz diffusion cell. In vivo pharmacodynamic study was carried out by determining the index of analgesia (increase in response time to thermal stress as percentage of basal response time). Tail flick method was employed to measure both the degree of analgesia and its duration of action. The prepared microspheres were white, free flowing, and spherical in shape with a mean particle size of $50 \mu \mathrm{m}$. In vitro release study of the micro-spheres in aqueous media was found to extend the release of DFS beyond 24 hours with DFS and EC ratio 1:3. The plot of log percentage remaining to be released vs. time gave a linear relationship indicating first-order release kinetics. The in vitro release rate constant $\left(\mathrm{K}_{r}\right)$ for different microspheres varied between $0.1448 \mathrm{hr}^{-1}$ and $0.0256 \mathrm{hr}^{-1}$. A good correlation was obtained between $\mathrm{K}_{\mathrm{r}}$ and proportion of $\mathrm{EC}$ in the microspheres. In vivo pharmacodynamic studies indicated that the duration of analgesic action is prolonged beyond $24 \mathrm{hrs}$ in case of microsphere products of 1:3 ratio of DFS to $\mathrm{EC}$, whereas administration of marketed parenteral preparation showed activity only up to $11 \mathrm{hrs}$. Also, a good correlation was obtained between analgesic activity in vivo and cumulative percentage of drug release from the formulations.

Keywords: Diclofenac sodium, Ethyl cellulose, Parenteral sustained release, Microspheres.

\section{Introduction}

DFS, an effective non-steroidal anti-inflammatory and analgesic drug with its low oral bioavilability (60\%), short plasma half-life $(1.1-1.8 \mathrm{hrs})$, and low dose $(25-75 \mathrm{mg}$ thrice daily) is an ideal candidate for the formulation of parenteral sustained release drug delivery system in the

\footnotetext{
- For Correspondence

msaha@bits-pilani.ac.in
} 
management of acute and chronic pain and traumatic conditions ${ }^{1,2}$. A good amount of work have been reported in the literature on the development of oral sustained release drug delivery system for Diclofenac Sodium (DFS), including the work by our group ${ }^{3-5}$. However, very little work has been reported on the development of parenteral sustained release formulation. The efficacy of dosage regimen in such conditions depend on the ability of the parenterally administered sustained release formulation to provide an initial burst release of drug to facilitate rapid onset of action and then maintain a constant plasma drug level for prolonged period of time. Such a formulation will thereby decrease the dosing frequency, alleviate pain and suffering for longer duration and at the same time avoid systemic accumulation of the drug and related side effects ${ }^{6}$. Increased need for patient compliance, especially in chronic pain or postoperative conditions, and improving the therapeutic efficacy of the drug suggest the need for sustained release parenteral drug delivery system for DFS.

Sustained release parenteral formulations of DFS have been attempted at by only few workers and are not simple. Various techniques which have been utilized for this purpose include multiple emulsion system ${ }^{7}$, poly-lactic-co-glycolic acid copolymer microcapsules ${ }^{8}$, and in situ gel forming systems ${ }^{9}$. Ethyl cellulose (EC) has been widely used for the microencapsulation of a number of water-soluble drugs to retard the release rate or to improve the stability ${ }^{50-13}$.

In the present study microsphere based depot type formulations were designed for DFS, using varying proportion of EC as the retardant material, by phase separation coacervation technique. Physical characteristics, micromeritics, and in vitro release studies were carried out to evaluate the release characteristics of DFS from these microsphere-based formulations. In vivo pharmacodynamic studies were carried out on animal (albino rat) model to measure the degree and sustained nature of the analgesia produced by tail-flick method (analgesiometer), wherein, the 
index of analgesia was calculated as increase in response time as percentage of basal response time and compared with conventional market preparation. A regression analysis was performed between index of analgesia and cumulative percentage drug released in vitro, up to time for $60 \%$ of drug release.

Table 1. Physical characteristics of the microspheres

\begin{tabular}{llll}
\hline Formulations & DMS1 & DMS2 & DMS3 \\
\hline $\begin{array}{l}\text { Components } \\
\begin{array}{l}\text { Physical Properties } \\
\text { of Microspheres }\end{array}\end{array}$ & $\begin{array}{l}\text { DFS:EC (1:1) } \\
\text { White, Spherical, } \\
\text { Free flowing }\end{array}$ & $\begin{array}{l}\text { DFS:EC (1:2) } \\
\text { White, Spherical, }\end{array}$ & $\begin{array}{l}\text { DFS:EC (1:3) } \\
\text { White, Spherical, } \\
\text { Free flowing }\end{array}$ \\
$\begin{array}{l}\text { Particle Size } \\
\text { (mean diameter in }\end{array}$ & $49.94 \pm 12.83$ & $51.03 \pm 11.19$ & $52.72 \pm 14.15$ \\
$\mu \mathrm{m})$ & & \\
$\begin{array}{l}\text { Drug Content } \\
\text { (in mg/ g of the } \\
\text { microspheres) }\end{array}$ & $585.23 \pm 9.8$ & $389.11 \pm 3.2$ & $324.78 \pm 7.4$ \\
$\begin{array}{l}\text { In-vitro release rate } \\
\text { constant }\left[\left(\mathrm{K}_{\mathrm{r}}\right) \mathrm{hr}^{-1}\right]\end{array}$ & 0.1418 & & \\
\hline
\end{tabular}

Average of hundred microspheres \pm S.D.

${ }^{b}$ Average of three batches \pm S.D.

\section{Results and discussions}

Supplied DFS characterized by various official tests of identification ${ }^{14}$ and analyzed by UV spectrophotometric method passed the tests of identification and analysis. Studies on effect of various formulation excipients like ethyl cellulose and cyclohexane on the stability of DFS suggest that the formulation additives, in the concentration used, did not affect the stability and UV absorbency profile of DFS. Physical characteristics and drug content per gram of formulated microspheres are presented in Table 1. The microspheres were white, free flowing and spherical in shape. The mean particle size varied between $49.94 \mu \mathrm{m}$ to $52.72 \mu \mathrm{m}$ for different formulations 
of DFS-EC microspheres (Table 1). The drug content per gram of the microspheres, as expected, decreased as proportion of the EC was increased.

Table 2. Regression equation between index of analgesia and cumulative percentage of drug released from designed microspheres

\begin{tabular}{llllll}
\hline Formulation & Equation* & n & r & s & F \\
\hline DMS1 & IA $=\begin{array}{c}5.2094( \pm 0.7995) \times \% \mathrm{DR}- \\
57.7214( \pm 33.3964)\end{array}$ & 6 & 0.9559 & 20.4131 & 42.4560 \\
& $\mathrm{IA}=\begin{array}{l}3.5463( \pm 0.1268) \times \% \mathrm{DR}- \\
33.1170( \pm 6.3886)\end{array}$ & 9 & 0.9956 & 8.3438 & 781.7274 \\
DMS2 & $\mathrm{IA}=\begin{array}{l}3.0568( \pm 0.1547) \times \% \mathrm{DR}- \\
12.7540( \pm 6.3781)\end{array}$ & 12 & 0.9874 & 9.3725 & 390.2293 \\
DMS3 & & & & \\
\hline
\end{tabular}

IA- Index of analgesia

$\%$ DR-Cumulative percentage of drug release at different time up to time for $60 \%$ DFS release

$n$ - Number of data points used in the correlation

$\mathbf{r}$ - Correlation coefficient

s - Residual standard deviation

F- $\delta$-ratio between the variance of calculated and observed values of the dependent variable

* Data in the parentheses of the equation indicate the $95 \%$ confidence intervals

In vitro release study of the microspheres, performed in phosphate buffer of $\mathrm{pH} 6.8$ showed that the duration of DFS release was extended beyond $24 \mathrm{hrs}$ in case of DMS3 whereas in DMS1 and DMS2 the release were much faster. The plot of log percentage remaining to be released vs. time gave a linear relationship (Figure 1) suggesting first-order release kinetics of DFS from the EC microspheres. The in vitro release rate constant $\left(\mathrm{K}_{\mathrm{r}}\right)$, as obtained from the slope of the plot and enlisted in Table 1, varied between $0.1448 \mathrm{hr}^{-1}$ (DMS1) and $0.0256 \mathrm{hr}^{-1}$ (DMS3). Since the EC barrier layer is insoluble in water, the release of the drug probably occurred through partitioning and/or diffusion. Increasing the proportion of EC slowed the rate of release. About 98\% and 93\% DFS was released in 24 hours in case of DMS1 [DFS: EC (1:1)] and DMS2 [DFS: EC (1:2)] respectively. However, in case of DMS3 [DFS: EC (1:3)] the duration of release was extended beyond $24 \mathrm{hrs}$, with only $56 \%$ release at the end of $24 \mathrm{hrs}$. 
Correlation equation obtained between $\mathrm{K}_{\mathrm{r}}$ and proportion of $\mathrm{EC}(\% \mathrm{EC})$ in the microspheres (calculated from the drug content data of table1) is presented below:

$$
\begin{gathered}
\mathrm{K}_{\mathrm{r}}=-0.0045( \pm 0.0018) \times \% \mathrm{EC}+0.3184( \pm 0.1013) \\
\mathrm{n}=9, \mathrm{r}=0.9169, \mathrm{~s}=0.0339, \mathrm{~F}=5.2810
\end{gathered}
$$

In the above equation, $\mathrm{n}$ is the number of data points used in the correlation, $\mathrm{s}$ is the residual standard deviation, $\mathrm{r}$ is the correlation coefficient, and $\mathrm{F}$ is the $\delta$-ratio between the variance of calculated and observed values of the dependent variable. Data in the parentheses indicate the $95 \%$ confidence intervals. A good correlation was obtained between $K_{r}$ and proportion of EC (\%EC) in the microspheres, obtained from the drug content data, as is evident from high correlation coefficient value of 0.9169 and very low residual standard deviation value. In addition, no significant difference was observed in the release profile of different batches of microspheres, indicating that the manufacturing process employed is reliable and reproducible. In addition, the study of stability and release profile at different interval of time, up to 12 months of storage, indicated the stability of the drug, unaltered physical characteristics of microspheres and release profiles.

The in vivo pharmacodynamic studies further confirmed the observed sustained release character of DFS from the designed formulations. Group 0 animals $(0.6 \mathrm{~mL}$ of sterile water for injection) showed a response time of $4.0( \pm 0.1)$ sec throughout the duration of the studies which was considered the basal response time. The plot between index of analgesia and time in rat upon i. $m$. administration of aqueous dispersion of the designed microspheres of DFS are presented in Figure 2. An immediate release parenteral preparation of DFS selected from the Indian market was used as positive control in the study. The studies revealed that in case of group 1 animals (market preparation) the time for onset of action is $0.5 \mathrm{hrs}$ with a $\mathrm{t}_{\max }$ (time for peak analgesic 
effect) of $2 \mathrm{hrs}$ and the duration of action was around $11 \mathrm{hrs}$ as is usually seen. However, in case of group 2 animals [DFS: EC (1:1)] the time for onset of action was $0.5 \mathrm{hr}$ with a $\mathrm{t}_{\max }$ of about 6 hrs, but the duration of action was not extended beyond $12 \mathrm{hrs}$. In case of group 3 animals [DFS: EC (1:2)] the time for onset of action was $0.5 \mathrm{hr}$ but the duration of action was extended beyond $20 \mathrm{hrs}$. Whereas, in case of group 4 animals [DFS: EC (1:3)] the time for onset of action was around $1 \mathrm{hr}$ but the duration of action was extended beyond $24 \mathrm{hrs}$ with only $56 \%$ release and near constant analgesic activity. The results indicate slow and extended duration of action for all the microsphere products. However, in case of DMS3 the release pattern became nearly zero order around 24 hours time as observed in both in vitro and in vivo studies. Further, on continuous macroscopic and microscopic observation of the site of administration of the aqueous dispersion of designed DFS microspheres, no tissue necrosis was observed.

Further, regression equations between index of analgesia (IA) and cumulative percentage of drug release (\%DR) at different time up to time for $60 \%$ DFS release in vitro for various formulations were calculated and are presented in Table 2. A good correlation was obtained between analgesic activity in vivo and cumulative percentage of drug release from the formulations, upto a period for $60 \%$ of the drug release. The correlation coefficient (r), as given in table 2 , varied from 0.9874 to 0.9956 indicating a very high in vivo and in vitro correlation. A significant difference (at $\mathrm{p}<$ 0.05 ) was observed in the in vitro release data as well as in vivo pharmacodynamic profile between various designed formulations using one-way analysis of variance and Tukey's multiple range tests.

It can be concluded that microsphere based depot type formulation is a feasible technique for preparing parenteral sustained release preparation of DFS. The EC based microspheres of DFS were stable, of good physical properties and exhibited reproducible release kinetics across the batches, indicating the reliability and reproducibility of the manufacturing process. The duration 
of DFS release from the microspheres was extended upon increasing the proportion of EC. The result of this study should advance the rational basis to simulate the benefits of intravenous drug infusions without its potential hazards, discomforts to the patients through the development of depot type parenteral sustained release formulations.

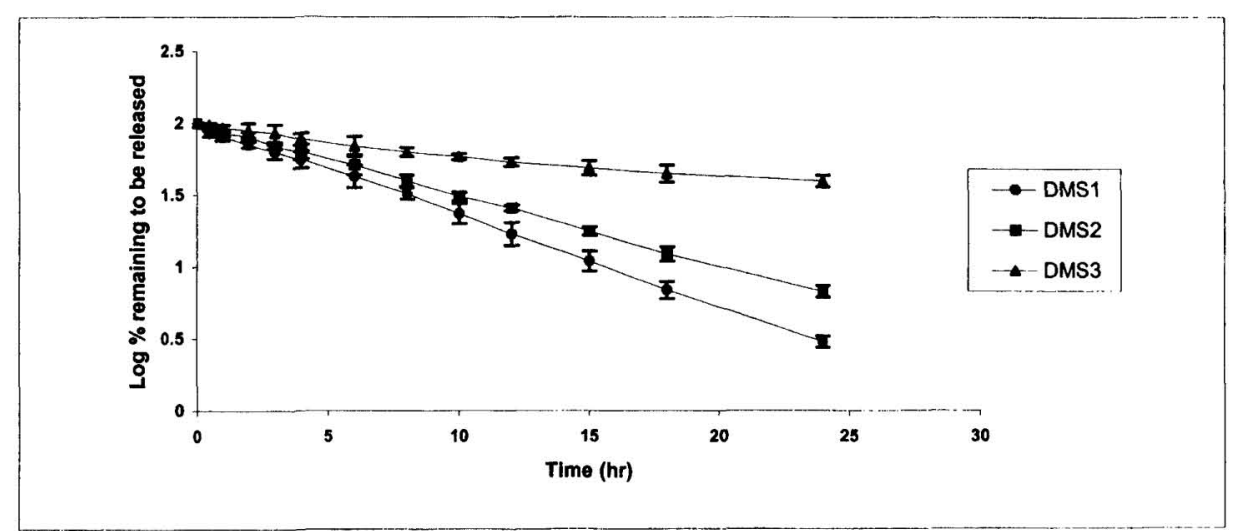

Figure 1. Release profile of DFS microspheres with varying proportion of EC. Data represents the average of triplicate release studies with standard deviation.

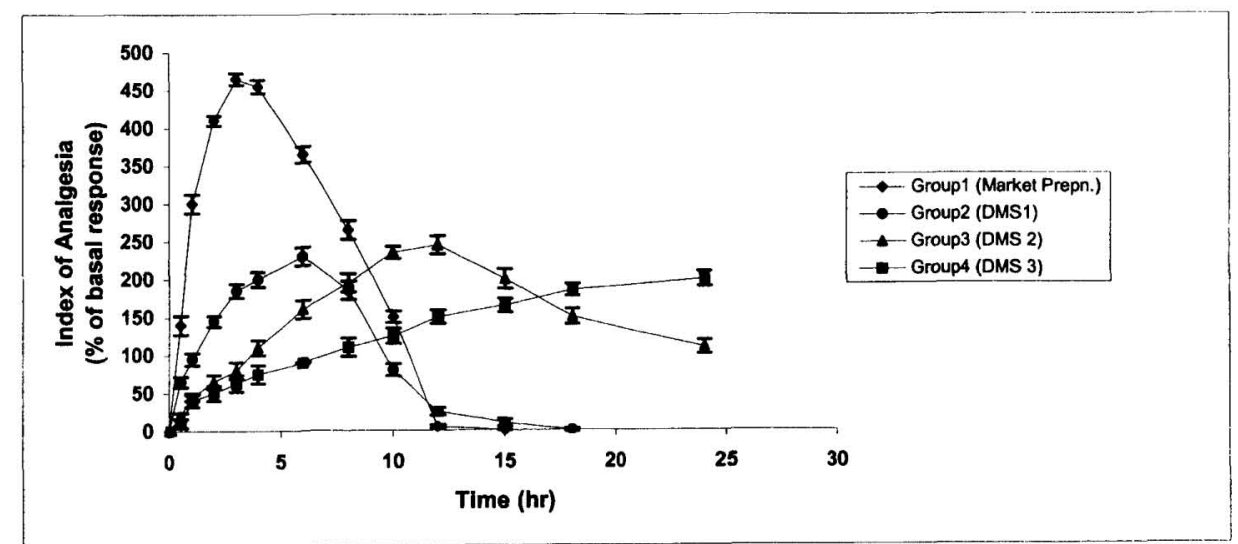

Figure 2. Profile of index of analgesia in rat upon $i . m$. administration of the aqueous dispersion of the designed formulations of DFS and an ordinary i. m. market preparation. Data represents the average of six animals with standard deviation. Average basal response time of the animals used in the study was $4.0 \pm 0.1 \mathrm{sec}$. 


\section{Experimental}

\subsection{Materials}

Diclofenac sodium I.P. was obtained as gift sample from Torrent Pharmaceuticals Ltd., Ahmedabad, India. Ethyl cellulose and all other chemicals and reagents used in the study were of pharmaceutical or analytical grade.

\subsection{Characterization of bulk drug}

Bulk drug was characterized by various official tests of identification and analyzed by UV spectrophotometric method (Jasco, UV-Vis spectrophotometer; model -7800) at $276 \mathrm{~nm}$ in aqueous medium. Effect of various excipients like ethyl cellulose and cyclohexane on the stability and analysis of DFS was also studied.

\subsection{Preparation of microspheres}

Phase separation-coacervation method was employed to formulate microspheres of DFS using different ratio of DFS and EC [1:1 (DMS1), 1:2 (DMS2), and 1:3 (DMS3)]. EC was dissolved in cyclohexane by heating to a temperature of $80^{\circ} \mathrm{C}$. Finely pulverized DFS was dispersed in the solution of EC in cyclohexane with vigorous stirring. Phase separation was induced by reducing the temperature while maintaining vigorous stirring. The product obtained after drying was size reduced and passed through very fine sieve. The required dose of microspheres was dispersed in sterile triple distilled water at the time of administration. To study batch reproducibility three batches of each formulation were prepared and evaluated for release profile of DFS. These batches of the formulations were re-evaluated at 3, 6 and 12 months interval to study the effect of storage under ambient conditions on the stability and release profile of the drug from the EC microspheres.

\subsection{Physical characterization of the microspheres}

The microspheres prepared were studied for appearance and size distribution using optical 
microscopy. The drug content in the microspheres was determined by dissolving accurately weighed amount of the formulation in little amount $(<5 \mathrm{~mL})$ of methanol to dissolve the $\mathrm{EC}$ coat. To this $20-25 \mathrm{~mL}$ of triple distilled water was added and then the solution heated to evaporate the methanol. The solution was filtered to remove insoluble EC, suitably diluted and analyzed by UV spectrophotometric method at $276 \mathrm{~nm}$.

\subsection{In vitro release study}

The in vitro release from the designed formulations was studied using modified Franz diffusion cell ${ }^{15}$. The formulation equivalent to $75 \mathrm{mg}$ of DFS was placed in donor chamber in contact with the dissolution media (178 $\mathrm{mL}$ phosphate buffer of $\mathrm{pH} 6.8)$. The semipermeable membrane was pre-hydrated with dissolution media for 30 mins. A $3 \mathrm{~mL}$ sample were withdrawn and replaced with fresh media at different time interval and analyzed after suitable dilution. The in vitro studies were carried out in triplicate.

\subsection{In vivo pharmacodynamic study}

Thirty albino rats of either sex (200-250gms) were divided into five groups of six rats each and fasted for $4 \mathrm{hrs}$ (water adlibitum) before the experiments. The practices of experimental animal handling were properly followed before, during and after experimentation according to the "Principles of Laboratory Animal Care" (NIH Publication \# 85-23, revised 1985). The experimental protocol and usage of the animal was approved and monitored by the Institutional Animal Ethics Committee of Birla Institute of Technology and Science, Pilani. The index of analgesia was measured as the increase in response time to thermal stress as percentage of basal response time. Tail Flick Method (using analgesiometer) was employed to measure both the degree and sustained nature of the analgesia induced.

The volume of preparation injected was kept constant at $0.6 \mathrm{~mL}$ for all the groups treatment. In case of treatment with the designed microspheres, the dose of the drug per $\mathrm{Kg}$ of the body 
weight of the animal was doubled as compared to that of market preparation so as to get sufficient initial release for rapid onset as well as sustained nature of the analgesic action. The treatment given to the five groups were: Group 0 - placebo [0.6 $\mathrm{mL}$ sterile water for injection], Group 1 market preparation [dose- $6.75 \mathrm{mg} \mathrm{DFS} / \mathrm{Kg}$ of the body wt. of $2.5 \mathrm{mg} \mathrm{DFS} / \mathrm{ml}$ of aqueous solution; $i$. m.], Group 2 -DMS1 [dose- $13.5 \mathrm{mg} \mathrm{DFS} / \mathrm{Kg}$ of the body wt. of $5.0 \mathrm{mg} \mathrm{DFS} / \mathrm{ml}$ of aqueous dispersion; i. m.], Group 3 - DMS2 [dose- $13.5 \mathrm{mg} \mathrm{DFS/} \mathrm{Kg}$ of the body wt. of $5.0 \mathrm{mg}$ $\mathrm{DFS} / \mathrm{ml}$ of aqueous dispersion; i. m.], Group 4-DMS3 [dose- $13.5 \mathrm{mg} \mathrm{DFS} / \mathrm{Kg}$ of the body wt. of $5.0 \mathrm{mg} \mathrm{DFS} / \mathrm{ml}$ of aqueous dispersion; i. m.].

\subsection{Data analysis}

All values presented in this study are average of replicate experiments at the same time points. Least square regression equations and the correlation coefficients were calculated using Microsoft Office 2000, Excel package. Difference in in vitro release as well as in vivo pharmacodynamic profile of various designed formulations were tested statistically ${ }^{16}$ using oneway analysis of variance and Tukey's multiple range test at $\mathrm{p}<0.05$.

\section{Acknowledgements}

The authors are thankful to Torrent Pharmaceuticals Ltd., Ahmedabad, India, for the generous gift samples of diclofenac sodium. This work was partially supported by a research grant from University Grants Commission, New Delhi, India.

\section{References}

1. Todd A., Sorkin, E. M., (1988) Drugs, 35, 244.

2. Small R. E., (1989) Clin. Pharmacol., 8, 545.

3. Sajeev C., Saha R. N., (2001) Drug Dev. Res., 8(1), 1.

4. Saha R. N., Sajeev C., Sahoo J., (2001) Drug Del., 8(3), 149.

5. Sajeev C., Vinay G., Archna R., Saha R. N., (2002) J. Microencaps., 19(6), 753. 
6. Marsh C. C., Sachuna A. A., Sundstrom, W. R. (1986) Pharmacotherapy, 6(1), 10.

7. Nakhare S., Vyas S. P. (1994) Pharmazie, 49, 842.

8. Chandrashekhar G., Udupa N., (1996) J. Pharm. Pharmacol., 48, 669.

9. Chowdary K. P. R., Rao G. N., (1984) Indian J. Pharm. Sci., 46(6), 213.

10. Bergisadi N., Gurvardar D., (1989) Acta Pharma. Turc., 31(4), 161.

11. Donbrow M. A., Benita S. (1977) J. Pharm. Pharmacol., 29 (Suppl), 4P.

12. Nasa S. L., Yadav S., (1989) East. Pharm., 32, 133.

13. Kasai S., Koishi M., (1977) Chem. Pharm. Bull., 25, 314.

14. Indian Pharmacoepia, (1996) Controller of Publication, New Delhi, India, $4^{\text {th }}$ edn. Vol-I, p242.

15. Chien Y. W., Keshary, P. R., Huang Y. C., Sarpotdar P. P., (1983) J. Pharm. Sci., 72, 928.

16. Bolton S. (1997) Pharmaceutical statistics: Practical and Clinical Application, $3^{\text {rd }}$ edn., Marcel Dekker, New York, p. 153, p. 216. 